\title{
A systematic review of load control in football using a Global Navigation Satellite System (GNSS)
}

\author{
Vitor Ayres Principe ${ }^{1,2,3}$ (1) , Rodrigo Gomes de Souza Vale ${ }^{1,2,3}$ (1) , Rodolfo de Alkmim Moreira Nunes ${ }^{1,2}$ (i) \\ ${ }^{1}$ Universidade do Estado do Rio de Janeiro, Programa de Pós-Graduação em Ciências do Exercício e do Esporte, Rio de \\ Janeiro, RJ, Brasil ; ${ }^{2}$ Universidade do Estado do Rio de Janeiro, Laboratório de Exercício e Esportes (LABEES), Rio de \\ Janeiro, RJ, Brasil; ${ }^{3}$ Universidade Estácio de Sá, Laboratório de Fisiologia do Exercício, Cabo Frio, Rio de Janeiro, RJ, Brasil.
}

Associate Editor: Dustin Oranchuk. Auckland University of Technology, Sports

Performance Research Institute New Zealand, SPRINZ, New Zealand

\begin{abstract}
This systematic review aimed to evaluate various Global Navigation Satellite Systems (GNSS) receivers, based on the frequency applied, the number of satellites available, and the dilution of precision (DOP) presented to measure football player load control. Method: The systematic review followed the PRISMA recommendations. Four hundred and eighty-five articles were selected from two online databases (Scopus and ISI Web of Science) over five years, with 21 studies selected for this review. In these studies, the GNSS frequency ranged from 5 to $18 \mathrm{~Hz}$, with $10 \mathrm{~Hz}$ as the most commonly used frequency. Results: Of the 21 selected studies, 20 presented the ideal horizontal dilution of precision (HDOP), and the number of satellites available varied from 5 to 20. There was no consensus on defining speed, acceleration, or deceleration zones. Conclusion: There was no uniformity in data collected from the devices. Most GNSS receivers do not adopt the international system of units (SI).
\end{abstract}

Keywords: load control; football; global navigation satellite system; systematic review; GNSS; GPS.

\section{Introduction}

Load control in training sessions and games is an essential strategy for reducing injuries and optimizing performance in football ${ }^{1}$. When quantifying athlete loads, it is possible to observe the amount of activity performed (athlete external load) as the primary determinant for individual physiological responses (athlete internal load) $)^{2}$.

Standard load control parameters have become part of the everyday life of football clubs around the world ${ }^{3}$, considering that since 2015 the International Football Association Board has allowed the use of wearable technologies during official matches.

Thus, quantifying the external loads in football includes evaluating the distance, speed, accelerations, and decelerations performed by the athlete, as well as the exposure time for each measured variable 4 . These external loads can be determined with the aid of electronic tracking systems divided into 1) outdoor positioning systems (OPS); 2) local positioning systems (LPS); and 3) image-based systems.

Through OPS, the Global Navigation Satellite System (GNSS) calculates the athlete's position through trigonometry between satellites. The accuracy of the information depends on factors such as the number of satellites connected to each device and the dilution of precision (DOP), which provides a measurement of the GNSS signal accuracy, determined by the position of satellites in the sky ${ }^{6}$.

The satellites that are further away in the sky, provide the lowest error triangulation, and, consequently, lower DOP, while the closest satellites result in significant error triangulation, with a higher DOP. If more than four satellites are used, a three-dimensional location is calculated ${ }^{7}$.

GNSS systems establish autonomous geospatial positioning through the use of artificial satellites. In this sense, the US global positioning system (GPS) and the Russian Global Navigation Satellite System are considered fully operational and of global reach (GLONASS) ${ }^{8}$.

In addition to the technological development and the enormous amount of research using GNSS devices ${ }^{9,10}$, the extensive use of this technology deserves further scientific research deepening the analysis of the validity and reliability of the system used.

However, in general, sports studies using devices with GNSS technology only observe and provide contributions to the behavior of the variables collected ${ }^{11,12}$ disregarding the technological implications for data accuracy. As such, several review studies have failed to address the satisfactory form of the number of satellites that are closely linked to data quality, and also lack analysis of variations in units of measurements and the data analysis methods used. Nevertheless, the studies by Rago et al. ${ }^{13}$ provide an information basis on which to compose this review.

Thus, this systematic review aimed to evaluate the different types of Global Navigation Satellite Systems (GNSS) receiver that exists on the market as GPS based on the applied sampling frequency, the number of satellites available, and the dilution of precision (DOP) presented to measure load control in football players. The data analysis methods used on the GPS variables measured will also be observed. 


\section{Methods}

A systematic review of the literature available on two online databases on the load control of football players using a Global Navigation Satellite System (GNSS) to measure the training loads or games was carried out. The study was approved by the Research Ethics Committee of the Pedro Ernesto University Hospital (Hospital Universitário Pedro Ernesto - HUPE) of the Rio de Janeiro State University (UERJ) under number 10529119.8.0000.5259.

\section{Study Design}

This systematic review was conducted according to PRISMA guidelines (Preferred Reporting Items for Systematic Review and Meta-analysis) ${ }^{14}$. The searches were conducted on two interdisciplinary electronic databases (Scopus and ISI Web of Science) to identify articles over a period of five years (January 2015 to December 2019). The final search of the databases was conducted on December $20^{\text {th }}, 2019$. The related search terms were: Soccer, Football, Load Control, Monitoring Load, Player load, Training Load, Matches Load, Global Position System, GPS, and Wearable Technology. The search method uses Bibliometrics, and Boolean operators 'AND' and 'OR' between terms to construct the final search phrase. Thus, 485 articles were identified, of which 74 were excluded for repetition and 390 papers were outside the scope of the study.

\section{Study Eligibility}

All results in the electronic search were initially exported to Mendeley ${ }^{\circledR}$ Desktop software. The identification of eligible studies followed a three-step process: (1) duplicate studies were removed; (2) studies that were out of scope were excluded after the title and abstract screening; if an assertive decision could not be made in this phase, the studies remained; and (3) the final stage was completed by three independent researchers and involved the removal of the studies by the exclusion criteria after complete screening of the text.

The eligibility criteria were based on the PICOS model in accordance with the PRISMA statement ${ }^{14}$. Study design: observational. Participants: competitive athletes (defined as university students, college, international, professional, experienced, semi-professional, national athletes). Interventions: external training load monitoring. Timing: minimum one day Setting: professional football.

The present study adopted the following inclusion criteria: 1) Written in English;2) The study was published as original research in a peer-reviewed journal; 3) Data reported only for football; 4) The sample consisted of competitive athletes, and 5) The use of a global navigation satellite system (GNSS) is mandatory.

The present study adopted the following exclusion criteria: 1) Impossible to download; 2) Gender not reported; 3) Did not involve competitive athletes; 4) Included other sports, even if reported along with football; 5) GPS indicators not in accordance with the Malone et al. ${ }^{9}$ classification; 6) Case studies, editorials, reviews, technical reports and inquires.

\section{Bias Analysis}

The quality of the studies was evaluated through the risk of bias, using the procedures adopted by Saw, et al. ${ }^{15}$, as shown in Table 1 . The study evaluations were applied by two independent, qualified researchers. In the case of dissenting assessments, the opinion of a third researcher was requested to make the final decision.

The scores were assigned based on the extent to which each criterion was met, up to a maximum possible score of 8 (low risk of bias). Studies with a risk of bias score equal to or less than four were considered inadequate and were excluded. Once the studies to be included had been selected, a review of the reference lists ${ }^{16}$ was carried out to identify additional peer-reviewed studies.

\section{Data Extraction}

After meeting the eligibility criteria for inclusion, the data from the selected articles were organized on a personalized spreadsheet, Microsoft ${ }^{\circledR}$ Excel version 16.31 for Mac. However, according to recent recommendations from Malone et al. ${ }^{9}$ and Varley et al. ${ }^{14}$, only articles that presented the records and details of the device brand and model, data acquisition frequency $(\mathrm{Hz})$, number of satellites, horizontal dilution of precision (HDOP), and software used for data acquisition, were analyzed and included in this review (Table 2). For further analysis, we identified the statistical tests used by the authors of the studies for comparison purposes.

Table 1 - Risk of bias

\begin{tabular}{|c|c|c|c|c|c|}
\hline & \multirow{2}{*}{ Criteria } & \multirow{2}{*}{ Definition } & \multicolumn{3}{|c|}{ Scoring } \\
\hline & & & $\mathbf{0}$ & 1 & 2 \\
\hline A & Peer-reviewed & A study published in a peer-reviewed journal & No & Yes & \\
\hline B & Number of participants & Number of players included in study findings & $<5$ & $5-50$ & $>50$ \\
\hline $\mathrm{C}$ & Population defined & Age, gender, sport, participation level, and experience stated & No & Partly & Yes \\
\hline $\mathrm{D}$ & Training or competition load described & Training or competition is undertaken during the study period & No & Partly & Yes \\
\hline $\mathrm{E}$ & GPS use & The use of GPS was described & No & Yes & \\
\hline
\end{tabular}

Adapted from Horsley et al. (2009) ${ }^{13}$ 
Table 2 - Effect of dilution of precision

\begin{tabular}{cccl}
\hline HDOP Level & \multicolumn{2}{c}{ Quality / Signals } & \multicolumn{1}{c}{ Description } \\
\hline$<1$ & Ideal & $\Uparrow \Uparrow$ & Maximum accuracy possible all times \\
$1-2$ & Excellent & $\Uparrow$ & Accurate measurements \\
$2-5$ & Good & $\Rightarrow$ & Measurements with appropriate precision \\
$5-10$ & Moderate & $\Leftrightarrow$ & Moderate quality recommended fixing \\
$10-20$ & Weak & $\Downarrow$ & Consider discarding all data \\
$>20$ & Poor & $\Downarrow \Downarrow$ & Very low accuracy, errors can be found at around $300 \mathrm{~m}$ \\
\hline
\end{tabular}

Adapted from Moen (1997) 7 and Wu et al (2012) ${ }^{40}$.

\section{Results}

\section{Overview of the Studies}

A systematic search was performed on the Scopus and ISI Web of Science electronic databases using time filters, publication type, and language, with the most recent update being in December 2019. Descriptors in Health Sciences (DeCS) and Medical Subject Headings (MeSH) were used. The search phrase was developed with the Boolean operators [OR] (between synonyms) and [AND] (between descriptors).

Initially, 485 records were identified. After removing duplicates (first screen), exclusion by title (second screen), and exclusion by abstract or full text, 342 studies met the inclusion criteria. During the screening of the full text, the main reasons for exclusion were: I) Impossible to download the article; II) Gender uninformed; III) Other sports different from football; IV) GPS indicator not in accordance with the Malone et al. ${ }^{9}$ classification; V) Different technologies that used GPS; and IV) Unoriginal studies (case study, editorial, review, or technical report), resulting in a total of 21 studies being included (Figure 1).

\section{Description and quality of the studies}

The studies were published from 2015 to 2019 in different leagues with different age participants. Of the 21 studies, 14 were performed with male football players, five with female football players, and one study included both genders. The most significant number of publications occurred in 2018 with 11, while 7 articles were published in 2019, prior to which numbers were small, with one study in 2015 and two in 2017. Among the 21 selected studies, the average score on the risk of bias was 6.9 , with no article reaching the maximum score of 8 points.

The deficiency presented was the non-inclusion of the age of the 45 athletes involved in the study by Trewin et al. ${ }^{18}$, in which researchers only reported that the athletes were part of a senior national team ranked in the top 10 in the world. Also, the duration of certain studies was omitted. Madison et al. ${ }^{19}$ portray their sample as semi-professional football players, and Scott and Lovell ${ }^{2}$ presented a provisional team for the FIFA women's world cup, which can be seen in greater detail in Table 3 .
The results presented in Table 4 demonstrate that among the 21 studies selected, data from the GPS were collected from at least one day of training up to two full seasons. Thus, the studies demonstrated that $75 \%$ carried out their investigations based on training, with some studies occurring during the competitive period of the athletes, while $25 \%$ used official matches for data collection. None of these studies included data from goalkeepers, and the studies by Knight et al. ${ }^{20}$ and Trewin et al. ${ }^{18}$ did not limit the time taken to acquire GPS data for their studies.

In the selected studies, the control of external load mainly in training on the physical conditioning of the athletes $(\sim 38 \%)$ is highlighted, either in the control of the activities proposed by the physical trainer or by physical tests applied for the specific use of the presented study. Applications in competitive games or official games are present in $\sim 47 \%$ of the studies presented (Table 4).

\section{GPS Variables}

For $\sim 66 \%$ of the studies, the total distance and sprinting represented the control of training volume. Even with divergences found in classifying the variables related to distances within specific speed ranges, we find that the variables of Very high-intensity $(\sim 28 \%)$ distance and High-intensity distance $(\sim 52 \%)$, and variables with low-speed intensity, are mainly used by the authors. Standing distance, walking distance, jogging distance, running distance, and fast running appeared little in the studies.

Of these studies, $\sim 33 \%$ also used the total number of accelerations for the same purpose, and only $\sim 23 \%$ used the total number of decelerations. Thus, it is worth noting that the studies diverged on how to quantify the loads related to accelerations and decelerations. As such, only four studies used a specific definition for acceleration and deceleration zones, calling them high intensity, moderate intensity, and low intensity.

Ten of the articles selected in this study were also concerned with some kind of control of the internal load of the athletes during the execution of the activities and their correlation with the external load data acquired with the aid of GPS. About $\sim 33 \%$ of the studies used HR for this control, $\sim 14 \%$ used the RPE scale, 9\% measured the athletes' oxygen volume, and $\sim 4 \%$ assessed lactate concentration in the blood. 
Variables such as Peak Speed, Average Metabolic Power, Average Speed, Maximum Acceleration, Relative Velocity, and Player Load were also found, but with a poor representation for external load control for the authors. Thus, in $47 \%$ of the studies, the authors expressed concern.

\section{GPS Information}

Catapult ${ }^{\circledR}$ is the company that supplied most of the equipment for measuring data. About $\sim 80 \%$ of the articles found in this study used equipment from this company, and its Minimax model represents $\sim 42 \%$ of use, surpassing the most recent Vector models, which do not appear in any of the studies, and the OptimEye line, which was used in $\sim 28 \%$ of the studies.

The frequency of data acquisition was mostly $10 \mathrm{~Hz}$, with the presence of one study using a frequency of $5 \mathrm{~Hz}$, and two studies using the Apex $18 \mathrm{~Hz}$ device from STATsports ${ }^{\circledR}$, as shown in Table 5. It is noteworthy that the accuracy of GPS devices has been extensively investigated, and has shown improved precision with a sampling frequency of up to
$10 \mathrm{~Hz}^{21,22}$; there are no additional benefits when increasing the acquisition frequency ${ }^{23}$.

\section{Statistical approach}

In their statistical development (Table 6), most of the studies did not use logarithmic transformation on their database, which is not a problem when using the standard approach to deal with distorted data. However, four studies have identified the use of transformation in the database to better suit the statistical model used.

Logarithmic transformation can reduce data variability and approximate the data to a normal distribution. If this approach is used, there are limitations when interpreting the relevance of the analysis of transformed data to the original data of interest ${ }^{24}$.

A total of 28 different statistical models were used in the studies found in this review. Given the different models with varying characteristics, it is difficult to make significant comparisons between the studies.

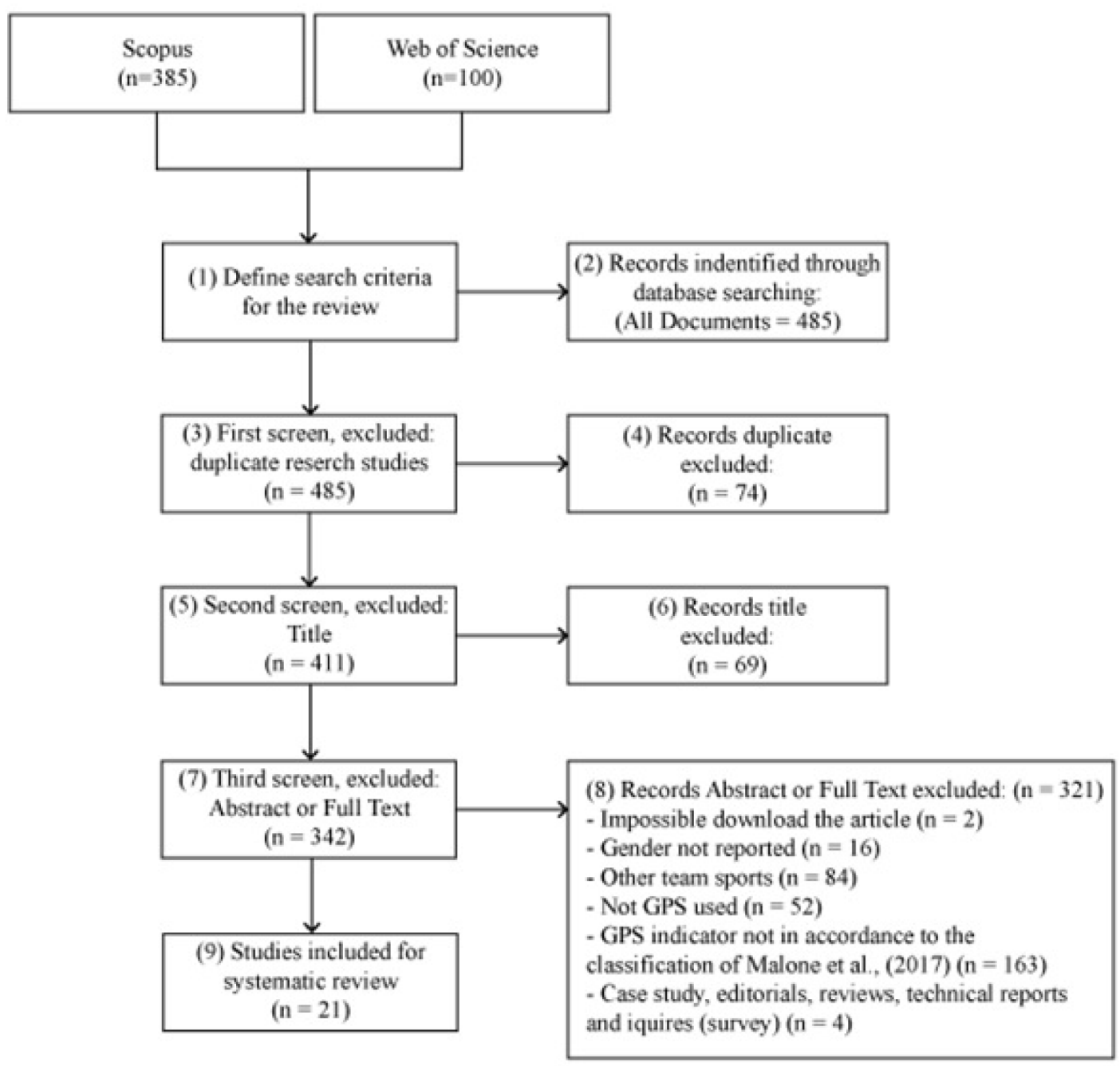

Figure 1 - The systematic review information flow described by phases according to the preferred reporting items for systematic reviews and meta-analyses (PRISMA). 
Table 3 - Quality Description of the 21 selected studies

\begin{tabular}{|c|c|c|c|c|c|c|c|c|c|}
\hline \multirow[b]{2}{*}{ Authors } & \multirow[b]{2}{*}{ Gender } & \multirow[b]{2}{*}{$\begin{array}{c}\text { Number of } \\
\text { Players (Age) }\end{array}$} & \multirow[b]{2}{*}{ Context } & \multicolumn{6}{|c|}{ Risk of Bias } \\
\hline & & & & $\mathbf{A}$ & B & $\mathbf{C}$ & D & $\mathbf{E}$ & Total \\
\hline Abbott et al. $(2018)^{22}$ & M & $46(19.1 \pm 1.2)$ & U23 Premier League Academy & 1 & 1 & 2 & 2 & 1 & 7 \\
\hline Abbott et al. $(2018)^{23}$ & M & $31(19.4 \pm 1.7)$ & U23 Premier League Academy & 1 & 1 & 2 & 2 & 1 & 7 \\
\hline Abbott et al. $(2018)^{24}$ & M & $19(18.2 \pm 1.1)$ & U21 Premier League Academy & 1 & 1 & 2 & 2 & 1 & 7 \\
\hline Abbott et al. $(2018)^{25}$ & M & $37(19.9 \pm 1.4)$ & U23 Premier League Academy & 1 & 1 & 2 & 2 & 1 & 7 \\
\hline Beato et al. $(2019)^{29}$ & $\mathrm{M} / \mathrm{F}$ & $20(21.0 \pm 2.0)$ & University Students & 1 & 1 & 2 & 2 & 1 & 7 \\
\hline Beato et al. $(2018)^{40}$ & M & $15(20.0 \pm 1.0)$ & University Students & 1 & 1 & 2 & 2 & 1 & 7 \\
\hline Curtis et al. $(2018)^{30}$ & M & $18(20 \pm 1)$ & NCAA Division I & 1 & 1 & 2 & 2 & 1 & 7 \\
\hline Fitzpatrick et al. $(2018)^{29}$ & M & $14(17.1 \pm 0.5)$ & U18 Premier League & 1 & 1 & 2 & 2 & 1 & 7 \\
\hline Jaspers et al. $(2018)^{31}$ & M & $35(23.2 \pm 3.7)$ & Netherlands First league & 1 & 1 & 2 & 2 & 1 & 7 \\
\hline Jones et al. $(2019)^{34}$ & M & $37(23 \pm 4)$ & English Football League One & 1 & 1 & 2 & 2 & 1 & 7 \\
\hline Knight et al. $(2015)^{17}$ & M & $14(22 \pm 4.1)$ & Australian domestic & 1 & 1 & 2 & 2 & 1 & 7 \\
\hline Kyprianou et al. (2019) ${ }^{41}$ & M & $12(16.3 \pm 0.8)$ & Elite youth football academy & 1 & 1 & 2 & 2 & 1 & 7 \\
\hline Madison et al. $(2018)^{16}$ & M & $10(23 \pm 5)$ & $\mathrm{NR}^{1}$ & 1 & 1 & 2 & 2 & 1 & 7 \\
\hline Massard et al. $(2018)^{42}$ & M & $23(21.4 \pm 3.8)$ & Australian Tier 2 club & 1 & 1 & 2 & 2 & 1 & 7 \\
\hline Meylan et al. $(2017)^{33}$ & $\mathrm{~F}$ & $20(18.2 \pm 0.7)$ & U20 women's national team & 1 & 1 & 2 & 2 & 1 & 7 \\
\hline Park et al. $(2019)^{38}$ & $\mathrm{~F}$ & $27(24.6 \pm 3.8)$ & USA women team & 1 & 1 & 2 & 2 & 1 & 7 \\
\hline Rago et al. (2019) ${ }^{32}$ & M & $13(25.8 \pm 3.5)$ & Italy's second-tier league & 1 & 1 & 2 & 2 & 1 & 7 \\
\hline Ramos et al. $(2019)^{28}$ & $\mathrm{~F}$ & $\begin{array}{c}17(15.6 \pm 0.5) \\
14(18.1 \pm 0.8) \\
17(27 \pm 4.5)\end{array}$ & Brazilian national teams & 1 & 1 & 2 & 2 & 1 & 7 \\
\hline Ramos et al. $(2017)^{27}$ & $\mathrm{~F}$ & $12(18 \pm 0.7)$ & U20 women's Brazilian team & 1 & 1 & 2 & 2 & 1 & 7 \\
\hline Scott et al. $(2018)^{2}$ & $\mathrm{~F}$ & $22(21.9$ to 39.5$)$ & $\mathrm{NR}^{2}$ & 1 & 1 & 2 & 2 & 1 & 7 \\
\hline Trewin et al. $(2018)^{15}$ & $\mathrm{~F}$ & 45 (NR) & $\mathrm{NR}^{3}$ & 1 & 1 & 1 & 1 & 1 & 5 \\
\hline & & & All studies mean & 1 & 1 & 1.95 & 1.95 & 1 & 6.9 \\
\hline
\end{tabular}

$\mathrm{M}=$ Male, $\mathrm{F}=$ female, $\mathrm{NR}=$ Not reported, $\mathrm{NR}^{1}=$ Semi-professional football players, $\mathrm{NR}^{2}=$ Representing a provisional squad for the 2015 Women's FIFA World Cup, $\mathrm{NR}^{3}=$ senior national team ranked top 10 in the world, A: Study published in a peer-reviewed journal $(\mathrm{No}=0$, Yes $=1$ ), B: Number of players included in study findings $(<5=0,5-50=1,>50=1), C=A g e$, gender, sport, participation level, and experience stated $(\mathrm{No}=0$, Partly $=1$, Yes $=1)$, D: Training or competition undertaken during the study period $(\mathrm{No}=0$, Partly=1, Yes=1), E: The use of GPS was described $(\mathrm{No}=0$, Yes=1). 
Table 4 - GPS data duration and application.

\begin{tabular}{|c|c|c|c|c|c|c|c|c|c|c|}
\hline \multirow{2}{*}{ Authors } & \multirow{2}{*}{ Duration } & \multicolumn{6}{|c|}{ Training Session } & \multicolumn{3}{|c|}{ Matches } \\
\hline & & $\mathbf{P C}$ & TeP & TP & SSG & $\mathbf{D}$ & $\mathbf{R C}$ & $\mathbf{F}$ & $\mathbf{C}$ & $\mathbf{O}$ \\
\hline Abbott et al. $(2018)^{22}$ & August 2016 to May 2017 & & & & & YES & & & & \\
\hline Abbott et al. $(2018)^{23}$ & 4 weeks in the pre-season period & YES & YES & YES & YES & & YES & YES & & \\
\hline Abbott et al. $(2018)^{24}$ & 6 weeks in the pre-season period & YES & & & & & & YES & & \\
\hline Abbott et al. $(2018)^{25}$ & 6 weeks in the pre-season period & YES & YES & & & & & YES & & \\
\hline Beato et al. (2019) $)^{29}$ & Data recorded in 2018 & YES & & & & & & & & \\
\hline Beato et al. $(2018)^{40}$ & NR & YES & & & & YES & & & & \\
\hline Curtis et al. $(2018)^{30}$ & 2015 (August to November) & & & & & & & & & YES \\
\hline Fitzpatrick et al. $(2018)^{29}$ & 6 weeks (August-September) & & & & & & & & YES & \\
\hline Jaspers et al. $(2018)^{31}$ & 2 seasons $2014-2015$ and $2015-2016$ & & & & & & & & YES & \\
\hline Jones et al. $(2019)^{34}$ & 2 seasons $2015-2016$ and $2016-2017$ & & & & & & & & YES & \\
\hline Knight et al. $(2015)^{17}$ & NR & & & & YES & YES & & & & \\
\hline Kyprianou et al. (2019) ${ }^{41}$ & 8 training sessions per week & & & & & & & & YES & \\
\hline Madison et al. $(2018)^{16}$ & 4 weeks & & & & YES & & & & & \\
\hline Massard et al. $(2018)^{42}$ & Pre-season & YES & & & & & & & & YES \\
\hline Meylan et al. $(2017)^{33}$ & 34 games & & & & & & & YES & & \\
\hline Park et al. $(2019)^{38}$ & Games between 2012 and 2015 & & & & & & & & & YES \\
\hline Rago et al. (2019) 32 & $15-25$ training sessions & YES & YES & YES & & & & YES & & \\
\hline Ramos et al. $(2019)^{28}$ & Official international competitions & & & & & & & & & YES \\
\hline Ramos et al. $(2017)^{27}$ & U-20 South American Championship & & & & & & & & & YES \\
\hline Scott et al. $(2018)^{2}$ & 1-day training camp & YES & & & & & & & & \\
\hline Trewin et al. $(2018)^{15}$ & NR & & & & & & & & & YES \\
\hline
\end{tabular}

$\mathrm{NR}=$ Not reported $\mathrm{PC}=$ Physical Conditioning, $\mathrm{Te}=\mathrm{P}=$ Technical Practices $\mathrm{TP}=$ Tactical Practices, $\mathrm{SSG}=$ Small-side Games, $\mathrm{D}=$ Drills, $\mathrm{RC}=\mathrm{Replication}$ of Competition, $\mathrm{F}=$ Friendly Matches, $\mathrm{C}=$ Competitive Matches, $\mathrm{O}=\mathrm{O}$ Official Matches. 
Table 5 - Device information

\begin{tabular}{|c|c|c|c|c|c|c|}
\hline \multirow{2}{*}{ Authors } & \multicolumn{6}{|c|}{ GPS } \\
\hline & Company & Model & Frequency & $\begin{array}{l}\text { Number of } \\
\text { Satellite }\end{array}$ & HDOP & Software \\
\hline Abbott et al. $(2018)^{22}$ & Catapult & Minimax 4.0 / GPS & $10 \mathrm{~Hz}$ & $>12$ & $<1 \Uparrow \Uparrow$ (ideal quality) & Sprint 5.1.5 \\
\hline Abbott et al. $(2018)^{23}$ & Catapult & OptimEye S5B / GPS & $10 \mathrm{~Hz}$ & $15 \pm 1$ & $0.8 \pm 1 \Uparrow \Uparrow$ (ideal quality) & Sprint 5.1.5 \\
\hline Abbott et al. $(2018)^{24}$ & Catapult & OptimEye S5B / GPS & $10 \mathrm{~Hz}$ & $15 \pm 1$ & $0.7 \pm 1 \Uparrow \Uparrow$ (ideal quality) & Sprint 5.1.5 \\
\hline Abbott et al. $(2018)^{25}$ & Catapult & OptimEye S5B / GPS & $10 \mathrm{~Hz}$ & $14.7 \pm 1.8$ & $0.8 \pm 0.1 \Uparrow \Uparrow$ (ideal quality) & Sprint 5.1.5 \\
\hline Beato et al. $(2019)^{29}$ & STATsports & Apex / multi-GNSS & $\begin{array}{l}10 \mathrm{~Hz} \\
18 \mathrm{~Hz}\end{array}$ & $18 \pm 2$ & $0.4 \pm 0 \Uparrow \Uparrow$ (ideal quality) & $\begin{array}{l}\text { Apex 2.0.2.4 } \\
\text { Apex 5.0 }\end{array}$ \\
\hline Beato et al. $(2018)^{40}$ & STATsports & Apex / multi-GNSS & $10 \mathrm{~Hz}$ & $18 \pm 2$ & $0.4 \pm 0 \Uparrow \Uparrow$ (ideal quality) & Apex 2.0.2.4 \\
\hline Curtis et al. $(2018)^{30}$ & Catapult & Minimax 4.0 / GPS & $10 \mathrm{~Hz}$ & $9 \pm 3$ & $1.6 \pm 1.3 \Uparrow \Uparrow$ (ideal quality) & Logan Plus 5.1.7 \\
\hline Fitzpatrick et al. $(2018)^{29}$ & Catapult & Minimax S4 / GPS & $10 \mathrm{~Hz}$ & $14.4 \pm 0.5$ & $0.81 \pm 0.10 \Uparrow \Uparrow$ (ideal quality) & Sprint 5.1.7 \\
\hline Jaspers et al. $(2018)^{31}$ & Catapult & $\begin{array}{l}\text { Minimax S4 / GPS } \\
\text { OptimEye S5 / GPS }\end{array}$ & $10 \mathrm{~Hz}$ & $\geq 8$ & $<1.5 \Uparrow$ (excellent quality) & Sprint 5.1.7 \\
\hline Jones et al. $(2019)^{34}$ & Catapult & Optimeye X4 /GPS & $10 \mathrm{~Hz}$ & $\geq 6$ & $<1.5 \Uparrow$ (excellent quality) & $\begin{array}{l}\text { Sprint 5.1.7 } \\
\text { Openfiel 1.11.2 }\end{array}$ \\
\hline Knight et al. $(2015)^{17}$ & Catapult & Minimax/GPS & $5 \mathrm{~Hz}$ & $>5$ & $<8 \Uparrow \Uparrow$ (ideal quality) & Logan Plus 4.4.0 \\
\hline Kyprianou et al. $(2019)^{41}$ & Catapult & OptimEye S5/ GPS & $10 \mathrm{~Hz}$ & $12.0 \pm 0.0$ & $0.68 \pm 0.04 \Uparrow \Uparrow$ (ideal quality) & Openfield 1.21 .1 \\
\hline Madison et al. $(2018)^{16}$ & STATsports & Apex / multi-GNSS & $18 \mathrm{~Hz}$ & 16 to 20 & $0.54 \pm 0.20 \Uparrow \Uparrow$ (ideal quality) & Apex 2.1.0.4 \\
\hline Massard et al. $(2018)^{42}$ & Catapult & Minimax S4 / GPS & $10 \mathrm{~Hz}$ & $\geq 9$ & $<1.25 \Uparrow \Uparrow$ (ideal quality) & Sprint 5.1.7 \\
\hline Meylan et al. $(2017)^{33}$ & Catapult & Minimax S4 / GPS & $10 \mathrm{~Hz}$ & $11.9 \pm 1.2$ & $0.96 \pm 0.10 \Uparrow \Uparrow$ (ideal quality) & Sprint 5.1.0.1 \\
\hline Park et al. $(2019)^{38}$ & Catapult & Minimax S4 / GPS & $10 \mathrm{~Hz}$ & 8 to 14 & $>2.0$ (no precision) & Sprint 5.1.7 \\
\hline Rago et al. $(2019)^{32}$ & QStarz & BT-Q1000 EX / GPS & $10 \mathrm{~Hz}$ & $14 \pm 1$ & $0.7 \pm 0.1 \Uparrow \Uparrow$ (ideal quality) & NR \\
\hline Ramos et al. $(2019)^{28}$ & Catapult & Minimax S5/ GPS & $10 \mathrm{~Hz}$ & $12.4 \pm 0.5$ & $0.75 \pm 0.3 \Uparrow \Uparrow$ (ideal quality) & Openfield \\
\hline Ramos et al. $(2017)^{27}$ & Catapult & Minimax S5/ GPS & $10 \mathrm{~Hz}$ & $15.5 \pm 0.5$ & $0.75 \pm 0.3 \Uparrow \Uparrow$ (ideal quality) & NR \\
\hline Scott et al. $(2018)^{2}$ & Catapult & OptimEye S5/ GPS & $10 \mathrm{~Hz}$ & $12.7 \pm 0.7$ & $0.90 \pm 0.14 \Uparrow \Uparrow$ (ideal quality) & Openfield 1.14.0 \\
\hline Trewin et al. $(2018)^{15}$ & Catapult & Minimax S4 / GPS & $10 \mathrm{~Hz}$ & $12.1 \pm 0.4$ & $0.94 \pm 0.04 \Uparrow \Uparrow$ (ideal quality) & Sprint 5.1 \\
\hline
\end{tabular}

$\mathrm{NR}=$ Not reported. 
Table 6 - Statistical approach

Authors Methods $\quad$ Software

Abbott et al. $(2018)^{22}$

Abbott et al. $(2018)^{23}$

Abbott et al. (2018) $)^{24}$

Abbott et al. (2018) ${ }^{25}$

Beato et al. $(2019)^{29}$

Beato et al. $(2018)^{40}$

Curtis et al. $(2018)^{30}$

Fitzpatrick et al. $(2018)^{29}$

Jaspers et al. $(2018)^{31}$

Jones et al. (2019)

Knight et al. (2015) $)^{17}$

Kyprianou et al. (2019) ${ }^{41}$

Madison et al. $(2018)^{16}$

Massard et al. $(2018)^{42}$

Meylan et al. $(2017)^{33}$

Park et al. $(2019)^{38}$

Rago et al. (2019) 32

Ramos et al. (2019) $)^{28}$

Ramos et al. (2017) $)^{27}$

Scott et al. $(2018)^{2}$

Trewin et al. $(2018)^{15}$
KS, SW, S, K e 2wA

KS, SW, S, K, 2wA e C

KS, SW, W, B e C

KS, SW, S, K, 2wA, B e C

SW e C

BS e t-T

WT e TK

LR, $\mathrm{P}$ e C

GEE

LMM e C

B e C

TOST

2wA, B, t-T e C

LMM, P, RE e SD

CV e P

KM, GMM, SC, RE e LS

CV e WS

$\mathrm{MB}$ e $\mathrm{C}$

$\mathrm{MB}$ e $\mathrm{C}$

LMM

CV e SWC
IBM SPSS Statistics 22

IBM SPSS Statistics 22

IBM SPSS Statistics 22

IBM SPSS Statistics 22

IBM SPSS Statistics 20

JASP 0.9.1

R Studio 3.2.5

NR

IBM SPSS Statistics 24

IBM SPSS Statistics 22

IBM SPSS Statistics 19

IBM SPSS Statistics 22

IBM SPSS Statistics 23

NR

IBM SPSS Statistics 23

IBM SPSS Statistics 23

NR

NR

IBM SPSS Statistics 23

MS Excel

*Log-Transformed, NR=Not reported, KS=Kolmogorov-Smirnov, SW=Shapiro-Wilk, S=Skewness, K=Kurtosis, 2wA=Two-way ANOVA, C=Cohen's, $\mathrm{W}=$ Wilcoxon signed-rank, $\mathrm{B}=$ Bonferroni adjustment, $\mathrm{BS}=$ Bayesian statistical, $\mathrm{t}-\mathrm{T}=\mathrm{T}$-test, $\mathrm{P}=\mathrm{Pearson}$ 's correlation, $\mathrm{LR}=\mathrm{Linear}$ regression, TOST=Two one-sided tests, $\mathrm{TK}=$ Turkey pos-hoc, $\mathrm{GEE}=$ Generalized estimating equations, $\mathrm{LMM}=$ Linear mixed model, $\mathrm{WT}=$ Welch test, $\mathrm{RE}=\mathrm{Random}$ effect, $\mathrm{SD}=\mathrm{Squared}$ differences post hoc, $\mathrm{CV}=$ Coefficient of variation, $\mathrm{KM}=\mathrm{K}$-means, $\mathrm{GMM}=$ Gaussian mixture model, $\mathrm{SC}=$ Spectral Clustering, $\mathrm{RE}=\mathrm{Random}$ effects, $\mathrm{LS}=$ least-squared difference post hoc, WS=Within-subject correlations, $\mathrm{MB}=$ Magnitude-based inference and $\mathrm{SWC}=$ Smallest worthwhile change 


\section{Discussion and implications for practice and research}

The present study summarized and analyzed 21 studies related to the load control of football players, in which $\sim 42 \%$ of the selected articles worked with young people $<20$ years old. In the 4 articles by Abbott, et al. ${ }^{25-28}$, the researchers worked with young male football players from the English Premier League, as did Fitzpatrick et al. ${ }^{29}$. Ramos et al. ${ }^{30,31}$, used the base of the Brazilian women's team.

The risk of bias in these studies was monitored according to the parameters shown in Table 1 and presented in Table 3 with an average of 6.9 points, whereby only the study by Trewin et al. ${ }^{18}$, did not present the average age of the studied group and did not present clear explanations regarding the context of the presentation of the work, as was also the case in the studies by Madison el al. ${ }^{19}$ and Scott and Lovell ${ }^{2}$.

Of the 21 studies selected and shown in Table 4, data from the GNSS systems were collected from at least 1 day of training up to two complete seasons, whereby $\sim 76 \%$ of the articles carried out their investigations based on training, with some studies occurring during the competitive period, and $\sim 23 \%$ only using official game data, according to Table 4 . None of these studies included data from goalkeepers.

In addition, the studies by Abbott et al. ${ }^{28}$, Beato et al. ${ }^{32}$, Curtis et al. ${ }^{33}$, Fitzpatrick et al. ${ }^{29}$, Jaspers et al. ${ }^{34}$, Knight et al. ${ }^{20}$, Madison et al. ${ }^{19}$, Rago et al. ${ }^{13}$, Ramos et al. ${ }^{27}$ and Scott et and Lovell ${ }^{2}$ presented some internal load monitoring. The studies by Fitzpatrick et al. ${ }^{26}$, Madison et al. ${ }^{16}$, and Scott and Lovell et al. ${ }^{2}$ used heart rate (HR) records as the only control of the internal load.

Jaspers et al. ${ }^{31}$ used the rating of perceived exertion (RPE), using the modified Borg CR-10 scale, and Rago et al. ${ }^{32}$ used the RPE using the Borg CR-100 scale. The studies by Beato ${ }^{29}$, Curtis et al. ${ }^{30}$, and Knight et al. ${ }^{17}$ used both HR and RPE for monitoring, with 1 of these studies also using blood lactate concentration as a form of control.

Thus, Curtis et al. ${ }^{30}$ also associated the maximum oxygen volume (VO2 max) as a way of understanding the internal changes caused by the exposure to external loads and Abbott et al. ${ }^{24}$ estimated oxygen volume (VO2) through field tests to assess maximum aerobic speed (MAS), which is strongly correlated with VO2 max.

This study has found three different measurements to define accelerations and two measurements for decelerations. According to Meylan et al. ${ }^{35}$ and Trewin et al. ${ }^{15}$, in women's football, accelerations are those greater than $2.26 \mathrm{~m} . \mathrm{s}^{-2}$. For Fitzpatrick et al. ${ }^{26}$, accelerations and decelerations are changed greater than 2 m.s ${ }^{-2}$, and for Jaspers et al. ${ }^{31}$, Madison et al. ${ }^{16}$ and Ramos et al. ${ }^{27,28}$ accelerations are greater than $1 \mathrm{~m} \cdot \mathrm{s}^{-2}$ and decelerations greater than $-1 \mathrm{~m} . \mathrm{s}^{-2}$.

Regarding the variables based on speed, $\sim 66 \%$ of the studies classify the Sprint variable as predominant for understanding the intensities of the actions in which the athletes are involved. However, the selected studies differ in how to classify and measure this variable. Values of $5.55 \mathrm{~m} . \mathrm{s}^{-1}$ to $7 \mathrm{~m} . \mathrm{s}^{-1}$ or 19.98 $\mathrm{km} \cdot \mathrm{h}^{-1}$ to $25.20 \mathrm{~km} \cdot \mathrm{h}^{-1}$ can be found in the studies.
Two studies present divergent points in their classifications when dealing with the lowest speeds performed by the athletes. Knight et al. (2015) ${ }^{17}$ define: Strolling distance $(<0.19$ $\left.\mathrm{km} . \mathrm{h}^{-1}\right)$; Walking distance $\left(0.70-7.00 \mathrm{~km} \cdot \mathrm{h}^{-1}\right.$ or $0.19-1.94 \mathrm{~m} . \mathrm{s}$ $\left.{ }^{-1}\right)$; Jogging distance (7.00-14.40 km.h ${ }^{-1}$ or 1.94-4.00 m.s $\left.{ }^{-1}\right)$; Running distance $\left(14.40-20.00 \mathrm{~km} . \mathrm{h}^{-1}\right.$ or $\left.4.00-5.55 \mathrm{~m} . \mathrm{s}^{-1}\right)$; and Fast running distance $\left(20.00-23.00 \mathrm{~km} . \mathrm{h}^{-1}\right.$ or 5.55-6.38 m.s $\left.\mathrm{s}^{-1}\right)$; while Curtis et al. $(2018)^{30}$ stipulate: Walking distance $(0.00$ $7.19 \mathrm{~km} . \mathrm{h}^{-1}$ or $\left.0.0-1.99 \mathrm{m.s}{ }^{-1}\right)$; Jogging distance (7.20-14.39 $\mathrm{km} . \mathrm{h}^{-1}$ or 1.99-3.99 m.s $\mathrm{s}^{-1}$ ); and Running distance (14.40-21.59 $k m \cdot h^{-1}$ or 3.99-5.99 m.s. ${ }^{-1}$ ).

This creates confusion when compared to other authors who present differing classifications. For Fitzpatrick et al. (2018) ${ }^{26}$, speed zones can be divided into distance at very high speed running (VHSD $>21.00 \mathrm{~km} . \mathrm{h}^{-1}$ ou $5.83 \mathrm{m.s}{ }^{-1}$ ), and distance at high speed running (HSD > $17.00 \mathrm{~km} . \mathrm{h}^{-1}$ ou $4.72 \mathrm{m.s}{ }^{-1}$ ), whereas Abbott et al. (2018) ${ }^{24}$ use VHSD (5.50-7.00 m.s ${ }^{-1}$ ) and HSD (4.20-5.50 m.s $\left.{ }^{-1}\right)$.

Jones et al. $(2019)^{36}$ suggest a classification of $<14.40 \mathrm{~km} . \mathrm{h}$

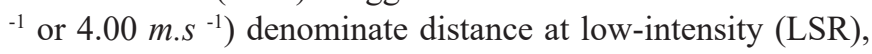
like Knight et al. ${ }^{17}$, who already classified it as below (14.40 $\mathrm{km} \cdot \mathrm{h}^{-1}$ ). Rago et al. ${ }^{32}$ add a moderate zone (distance at moderate-speed running - MSR) with speeds of (14.40-19.80 km.h ${ }^{-1}$, which was also demonstrated by Jones, et al. ${ }^{37}$, with MSR being less than $4.00 \mathrm{~m} \cdot \mathrm{s}^{-1}$.

There is a lack of standardization of the measurement units, with kilometers per hour $\left(\mathrm{km} . \mathrm{h}^{-1}\right)$ being used in some studies, which does not respect the International Measurement System (SI - Système international d'unités), which recommends using meters per second ( $\left.m . s^{-1}\right)$ to work with speed-related measurements. The SI is a systematized and standardized set of definitions for units of measurement, which aims to standardize and facilitate the measurements and the resulting international comparisons. Therefore, the lack of data standardization within the football context makes it very difficult for most members of the coaching staff to make correct interpretations ${ }^{38}$.

The accuracy of GPS devices has been extensively investigated. Improved accuracy is shown with a sampling frequency of up to $10 \mathrm{~Hz}^{17,22}$ and there are no additional benefits in increasing the acquisition frequency ${ }^{23}$.

However, the accuracy of the data depends on many factors (atmospheric refraction, multipath, ephemeris, and more), among which, the number of connected satellites and the horizontal precision dilution (HDOP) have been thoroughly discussed in studies by Malone et al. ${ }^{9}$ and Varley et al. ${ }^{17}$. However, it is worth mentioning that with the introduction of systems that use more than one constellation of satellites (GPS, GLONASS, Beidou, Compass, Galileo), neither the HDOP nor any of the DOPs is as important as before, since the use of several satellites at the same time generally leads to a DOP of less than four ${ }^{39,40}$.

Approximately $80 \%$ of the studies had an ideal HDOP classification, as shown in Table 5. Only the article by Park et $a{ }^{41}$ presents an HDOP description of greater than 2.0 and does not relate it to the magnitude of the effect, which makes it difficult to measure whether the data need to be discarded or corrected mathematically, according to the definitions of Moen et al. ${ }^{7}$ and $\mathrm{Wu}$ et al. ${ }^{42}$. 
The studies by Beato et al. ${ }^{29,43}$ use the HDOP values and number of satellites as the company's standard. Jaspers et al. ${ }^{31}$ reinforce that the values found are in accordance with the study by Malone et al. ${ }^{9}$.

The number of satellites found by the receivers is a point to be analyzed, given that depending on the geographic location of each study, it can be verified that in the selected studies the number varied from five to 20 satellites. As such, data acquisition in most studies was made through the software available with the devices, whereby only the studies by Ramos et al. ${ }^{27,28}$ and Rago et al. ${ }^{32}$ did not present how the GPS data was acquired. Despite going against the recommendations of Malone et al. ${ }^{9}$ and Varley el al. ${ }^{14}$, it was decided that keeping this study was reasonable because it is understood that data acquisition was made through the product software (Table 5).

The most used software for the applications of the statistical models of the 20 studies was the statistical package for the social sciences (Statistical Package for the Social Sciences), better known as SPSS of the International Business Machines Corporation (IBM). The most common tests were the Kolmogorov-Smirnov and Shapiro-Wilk normality tests, the measures of asymmetry dispersion and kurtosis, the bidirectional analysis of variance (ANOVA), and the size of the effect to measure the magnitude of the phenomenon, which can be seen in Table 6 . The studies by Kyprianou et al. ${ }^{44}$ and Massard et al. ${ }^{45}$ sought to escape traditional description by using equivalence testing through the Two one-sided test (TOST) and grouping techniques widely used in machine learning, respectively. This, therefore, demonstrates that data science is not yet standardized in the field of science applied to football. Moreover, few studies have used intelligent algorithms as an alternative form of data analysis.

\section{Study Limitations}

It is essential to consider some limitations to this review. In this paper, 21 studies measure the external load from the use of a GNSS device in both training and matches. There was no minimum data acquisition period, the description of the number of satellites and the dilution of horizontal precision (HDOP) were significant factors for the inclusion of studies in football ${ }^{9,14}$. Furthermore, it does not consider how to acquire acceleration or deceleration data. Either these were obtained through the accelerometer or from the derivation of speed. Thus, it is also limited by the type of activity developed, the period of the season, position in the championship, squad characteristics, weather conditions, and variability of the statistical tests used, among other situations that can directly interfere with both male and female athletes.

\section{Conclusion}

According to the aims of the study, this review identified several methodological variations in the presented studies, with the majority of studies using devices from a single manufacturer ( $\sim 80 \%$ of the studies found) and a frequency of data acquisition at $10 \mathrm{~Hz}$ in 18 studies. The number of satellites presented was within the ideal quality, with HDOP $<1$. However, one study did not demonstrate adequate accuracy and two studies showed that the new receiver models have a superior HDOP.

The lack of inaccuracy in the number of satellites, HDOP, and the software used to acquire data from the GNSS device are questionable, given that $\sim 14 \%$ of the selected studies are not transparent or do not present this information. The remaining $\sim 85 \%$ of the studies presented the average number of satellites and the average HDOP; however, they do not show where this information was obtained from.

Regarding the statistical approaches used in the studies, we also believe that using different models makes it difficult to analyze and compare the studies, as it does not permit a more analytical look to compare the findings found in the studies.

More specifically, the lack of classification for uniformity of speed, acceleration, and deceleration thresholds limits the comparisons between the studies, as does the non-standardization of the measurement units. Several studies have shown that researchers classify the zones of speed, acceleration, and deceleration differently and do not use the SI of measures as a way to facilitate the interpretation.

Thus, it is clear that the companies that develop GNSS devices establish the standard they find interesting to the market, establishing the measurement units they want and not allowing access to raw data, making standardization and intelligent acquisition a challenge to data processing.

Moreover, there is a lack of consistent information about women's football, whereby only the study by Park et al. ${ }^{38}$ (who presented an HDOP without precision) seeks to understand the areas of speed, acceleration, and deceleration for this context. The other studies with female football players use areas established in studies with male football players, which often do not match up to the studied reality.

This review enabled the identification of certain gaps in the context of load control in football players. These gaps were mainly observed in the application of load control methods in (1) male and female goalkeepers; (2) in the development of speed, acceleration, and deceleration zones relevant to each studied group (thus not using the standard devices available on the market); and (3) the use of new technologies to correct and improve data from GNSS devices.

\section{References}

1. Weston M. Training load monitoring in elite English soccer: a comparison of practices and perceptions between coaches and practitioners. Sci Med Footb 2018; 2: 216-224.

2. Scott D, Lovell R. Individualisation of speed thresholds does not enhance the dose-response determination in football training. $\mathrm{J}$ Sports Sci 2018; 36: 1523-1532.

3. Akenhead R, Nassis GP. Training load and player monitoring in high-level football: Current practice and perceptions. Int J Sports Physiol Perform 2016; 11: 587-593. 
4. Akenhead R, Harley JA, Tweddle SP. Examining the external training load of an English premier league football team with special reference to acceleration. J Strength Cond Res 2016; 30 : 2424-2432.

5. Rico-González M, Los Arcos A, Nakamura FY, Moura, FA, Pino-Ortega J. The use of technology and sampling frequency to measure variables of tactical positioning in team sports: a systematic review. Res Sport Med 2019; 00: 1-14.

6. Langley RB. Dilution of Precision. GPS World 1999; 10: 52-59.

7. Moen R, Pastor J, Cohen Y. Accuracy of GPS Telemetry Collar Locations with Differential Correction. J Wildl Manage 1997; 61: 530 .

8. Vaz JA, Pissardini RDS, Fonseca Junior ES Da. Comparação da cobertura e acurácia entre os sistemas GLONASS e GPS obtidas dos dados de observação de uma estação da Rede Brasileira de Monitoramento Contínuo. Rev Bras Cartogr 2013; 65: 529-539.

9. Malone JJ, Lovell R, Varley MC, Coutts AJ. Unpacking the black box: Applications and considerations for using GPS devices in sport. Int J Sports Physiol Perform 2017; 12: 18-26.

10. Rago V, Brito J, Figueiredo P, Costa J, Barreira D, Krustrup P, et al. Methods to collect and interpret external training load using microtechnology incorporating GPS in professional football: a systematic review. Res Sport Med 2019; 00: 1-22.

11. Cummins C, Orr R, O'Connor H, West C. Global positioning systems (GPS) and microtechnology sensors in team sports: A systematic review. Sport Med 2013; 43: 1025-1042.

12. Whitehead S, Till K, Weaving D, Jones B. The Use of Microtechnology to Quantify the Peak Match Demands of the Football Codes: A Systematic Review. Sport Med 2018; 48: 2549-2575.

13. Rago V, Krustrup P, Martín-Acero R, Rabelo A, Mohr M. Training load and submaximal heart rate testing throughout a competitive period in a top-level male football team. J Sports Sci. Epub ahead of print 2019. DOI: 10.1080/02640414.2019.1618534.

14. Liberati A, Altman DG, Tetzlaff J, Mulrow C, Gotzsche PC, Loannidis JP, et al. The PRISMA statement for reporting systematic reviews and meta-analyses of studies that evaluate health care interventions: Explanation and elaboration. PLoS Med; 6. Epub ahead of print 2009. DOI: 10.1371/journal.pmed.1000100.

15. Saw AE, Main LC, Gastin PB. Monitoring the athlete training response : subjective self-reported measures trump commonly used objective measures : a systematic review. Br J Sports Med 2016; 50: 281-291.

16. Horsley T, Dingwall O, Tetzlaff JM, et al. Checking reference lists to find additional studies for systematic reviews. Cochrane Database Syst Rev. Epub ahead of print 2009. DOI: 10.1002/14651858.MR000026.

17. Varley MC, Jaspers A, Helsen WF, Malone JJ. Methodological considerations when quantifying high-intensity efforts in a team sport using global positioning system technology. Int J Sports Physiol Perform 2017; 12: 1059-1068.

18. Trewin J, Meylan C, Varley MC, Cronin J. The match-to-match variation of match-running in elite female soccer. J Sci Med Sport 2018; 21: 196-201.

19. Madison G, Patterson SD, Read P, Howe L, Waldron M. Effects of small-sided game variation on changes in hamstring strength. J Strength Cond Res 2019; 33: 839-845.
20. Knight TJ, Scott BR, Jalilvand F, Lockie GR. The effect of changing player numbers on the physiological responses and time-motion characteristics of a soccer-specific training drill. Int J Perform Anal Sport 2015; 15: 452-470.

21. Varley MC, Fairweather IH, Aughey RJ. Validity and reliability of GPS for measuring instantaneous velocity during acceleration, deceleration, and constant motion. J Sports Sci 2012; 30: 121-127.

22. Rampinini E, Alberti G, Fiorenza M, Riggio M, Sassi R, Borges TO, et al. Accuracy of GPS devices for measuring high-intensity running in field-based team sports. Int J Sports Med 2015; 36: 49-53.

23. Scott M, Scott T, Kelly V. The Validity and Reliability of Global Positioning Systems in Team Sport: A Brief Review. J Strength Cond Res 2016; 30: 1470-1490.

24. Feng C, Wang H, Lu N, He, H, Lu Y, et al. Log-transformation and its implications for data analysis. Shanghai Arch Psychiatry 2014; 26: 105-109.

25. Abbott W, Brickley G, Smeeton NJ. Positional differences in GPS outputs and perceived exertion during soccer training games and competition. 2018. Epub ahead of print 2018.

26. Abbott W, Brickley G, Smeeton NJ, Smeeton NJ, Mills S. Individualizing acceleration in English premier league academy soccer players. J Strength Cond Res 2018; 32: 3503-3510.

27. Abbott W, Brickley G, Smeeton NJ. An individual approach to monitoring locomotive training load in English Premier League academy soccer players. Int J Sport Sci Coach 2018; 13: 421-428.

28. Abbott W, Brickley G, Smeeton NJ. Physical demands of playing position within English Premier League academy soccer. J Hum Sport Exerc 2018; 13: 285-295.

29. Fitzpatrick JF, Hicks KM, Hayes PR. Dose-response relationship between training load and changes in aerobic fitness in professional youth soccer players. Int J Sports Physiol Perform 2018; 13: $1365-1370$.

30. Ramos GP, Nakamura FY, Pereira LA, Junior WB, Mahseredjian F, Wilke CF, et al. Movement Patterns of a U-20 National Women's Soccer Team during Competitive Matches: Influence of Playing Position and Performance in the First Half. Int J Sports Med 2017; 38: 747-754.

31. Ramos GP, Nakamura FY, Penna EM, Wilke CF, Pereira LA, Loturco I, et al. Activity Profiles in U17, U20, and Senior Women's Brazilian National Soccer Teams During International Competitions: Are There Meaningful Differences? J Strength Cond Res 2019; 33: 3414-3422.

32. Beato M, De Keijzer KL, Carty B, Connor M. Monitoring fatigue during intermittent exercise with accelerometer-derived metrics. Front Physiol; 10. Epub ahead of print 2019.

33. Curtis R, Huggins R, Looney D, West AC, Fortunati A, Fortaine GJ, et al. Match Demands of National Collegiate Athletic Association Division I Men's Soccer. J Strength Cond Res 2018; 32: 2907-2917.

34. Jaspers A, Kuyvenhoven JP, Staes F, Frencken WGP, Helsen WF, Brink MS. Examination of the external and internal load indicators' association with overuse injuries in professional soccer players. $\mathrm{J}$ Sci Med Sport 2018; 21: 579-585.

35. Meylan C, Trewin J, McKean K. Quantifying explosive actions in international women's soccer. Int J Sports Physiol Perform 2017; 12: 310-315.

36. Jones RN, Greig M, Mawéné Y, Barrow J. The influence of short-term fixture congestion on position-specific match running 
performance and external loading patterns in English professional soccer. J Sports Sci 2019; 37: 1338-1346.

37. Jones RN, Greig M, Mawéné Y, Barrow J. The influence of short-term fixture congestion on position-specific match running performance and external loading patterns in English professional soccer. J Sports Sci 2019; 37: 1338-1346.

38. Gauthier-Villars. Comptes rendus des séances de la onzième conférence générale des poids et mesures. Paris, 1960.

39. Jyothirmaye S, Srinivas VS, Ramu B. Fast Satellite Selection Techniques and DOPs for Multi-GNSS Positioning S. 2019 URSI Asia-Pacific Radio Sci Conf 2019; 1-4.

40. Zhang Q, Chen Z, Rong F, Cui Y. Preliminary Availability Assessment of Multi-GNSS: A Global Scale Analysis. IEEE Access 2019; 7: 146813-146820.

41. Park LAF, Scott D, Lovell R. Velocity zone classification in elite women's football: where do we draw the lines? Sci Med Footb 2019; 3: 21-28.

42. Wu S, Liu Y, Liu L, Wang M. The Distributions of HDOP and VDOP in GNSS and a Corresponding New Algorithm of Fast Selecting Satellites. In: China Satellite Navigation Conference (CSNC) 2012 Proceedings, pp. 445-453.

43. Beato M, Coratella G, Stiff A, Iacono AD. The validity and between-unit variability of GNSS units (STATSports apex 10 and $18 \mathrm{~Hz}$ ) for measuring distance and peak speed in team sports. Front Physiol; 9. Epub ahead of print 2018.
44. Kyprianou E, Lolli L, Haddad H Al, Di Salvo V, Varley MC, Villanueva AM, et al. A novel approach to assessing validity in sports performance research: integrating expert practitioner opinion into the statistical analysis. Sci Med Footb; 3. Epub ahead of print 2019.

45. Massard T, Eggers T, Lovell R. Peak speed determination in football: is sprint testing necessary? Sci Med Footb 2018; 2: 123-126.

\section{Corresponding author}

Vitor Ayres Principe

Instituto de Educação Física e Desportos (IEFD), Universidade do Estado do Rio de Janeiro, Rua São Francisco Xavier, 524, Pavilhão João Lira Filho, Bloco F, $9^{\circ}$ andar, Maracanã, Rio de Janeiro, RJ, Brasil, 20550-900. Telephone: +55 (21) 2334-0639. E-mail: vitorprin@gmail.com

Manuscript received on April 12, 2020

Manuscript accepted on September 10, 2020

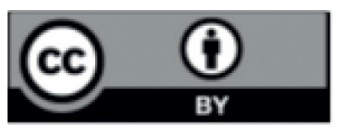

Motriz. The Journal of Physical Education. UNESP. Rio Claro, SP, Brazil - eISSN: 1980-6574 - under a license Creative Commons - Version 4.0 